\title{
Hunter's disease in a girl: association with X:5 chromosomal translocation disrupting the Hunter gene
}

\author{
J MOSSMAN, S BLUNT, R STEPHENS, E E JONES, AND M PEMBREY
}

Department of Clinical Biochemistry and Mothercare Unit of Paediatric Genetics, Institute of Child Health; Paediatric Research Unit, Guy's Hospital Medical School; and Hospital for Sick Children, Great Ormond Street, London and Department of Paediatrics, Hospital of St Cross, Rugby

SUMMARY We describe a 3 year old girl with the typical clinical features of the $X$ linked recessive condition, Hunter's disease. The diagnosis was confirmed by the pattern of urinary excretion of glycosaminoglycans and the absence of iduronate sulphatase activity in her fibroblasts. She also had an apparently balanced reciprocal chromosomal translocation $46 \mathrm{XX}, \mathrm{t}(\mathrm{X}: 5)$ with the $\mathrm{X}$ breakpoint being between q26 and q27. Pedigree analysis, and the normal iduronate sulphatase activity in the mother's fibroblasts, serum, and hair roots indicate that the affected child represents a new mutation. Since the parents' karyotypes are normal, it seems that the translocation disrupted the iduronate sulphatase gene itself, thus mapping this to Xq26-27 for the first time. The severe clinical features, not expected in a girl, may be explained by non-random $\mathrm{X}$ inactivation.

Hunter's disease (mucopolysaccharidosis type II) ${ }^{\mathbf{1}}$ is an $\mathrm{X}$ linked recessive disorder caused by deficiency of the lysosomal enzyme iduronate sulphatase. Affected boys accumulate dermatan sulphate and heparan sulphate in their tissues, causing coarsening of facial features, joint contractures, and in many instances shortness of stature, deafness, cardiac involvement, and intellectual deterioration. Heterozygous females do not usually show any clinical features of the disease. We report a girl who has the full clinical and biochemical features of Hunter's disease, and in addition has an apparently balanced $\mathrm{X}: 5$ chromosomal translocation. Neither parent has the translocation and the mother is not heterozygous for the Hunter gene. The proposed interpretation of these data is that the translocation 'breakpoint' disrupted the Hunter gene itself and, for the first time, maps this gene locus to Xq26-27.

\section{Case History}

A 3 year old girl, the third child of healthy nonconsanguineous English parents, was born at term, after a normal pregnancy and delivery, and weighed $3.8 \mathrm{~kg}$. An umbilical hernia was noticed at birth, but she was otherwise considered a normal baby. There were no neonatal problems. Her early develop- ment was normal and by age 14 months she was walking alone. Compared with her brothers her speech development was delayed, with first words with meaning spoken at age 18 months and sentences by age 2 years. Sphincter control was late and she does not yet have bowel control, but during the past year she had daytime control of micturition. She has had no illness apart from a mild attack of mumps at age 2 years. Although her parents have always considered her to be a normal child, they did think that her hearing was impaired and noticed that her stools have been getting looser and more frequent recently.

When she was admitted at age 2 years 9 months to the Hospital of St Cross, Rugby, for surgical repair of the umbilical hernia, her coarse facial features and skeletal abnormalities were noticed, and thought to by typical of a mucopolysaccharidosis. She was also found to have an enlarged liver. One of the authors (EEJ) thought her face was typical of Hunter's disease but because she was a girl, arranged for further investigations to be done at the Institute of Child Health.

On examination she had the typical clinical appearance of Hunter's disease (Fig. 1). Her height and weight were on the 97th percentile and her head circumference was on the 75 th percentile. She had a 


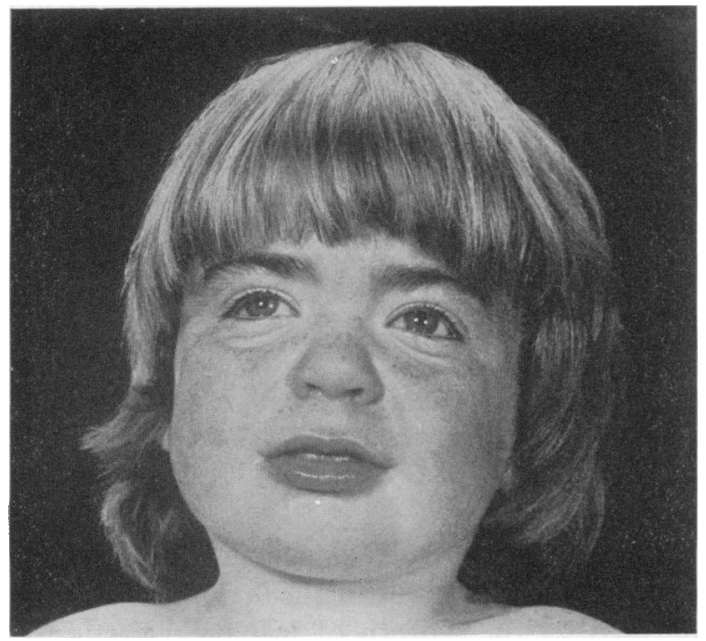

Fig. 1 Patient at age $3 \frac{1}{4}$ years. large tongue, coarse facial features, but clear corneae. There was hypertrichosis on her back, shoulders, and upper arms. She had large, broad fingers with fixed flexion at all distal phalangeal joints; some limitation of elbow movement; and small, outward placed scapulae. Her liver was enlarged to $6 \mathrm{~cm}$ below the right costal margin.

\section{Biochemical studies in the patient and her mother}

The urinary excretion of glycosaminoglycans (GAGs) by the patient at the age of 3 years was $65 \mathrm{mg} / \mathrm{mmol}$ creatinine compared with a range of $9-20 \mathrm{mg} / \mathrm{mmol}$ creatinine for age matched normal controls. Two dimensional electrophoresis of the constituent GAGs showed the presence of dermatan sulphate, heparan sulphate, and a heparin-like component, in addition to the normal chondroitin sulphate. This qualitative pattern is seen for both Hurler's disease and Hunter's disease, but the two types are differentiated by the relative proportions of heparan sulphate and the

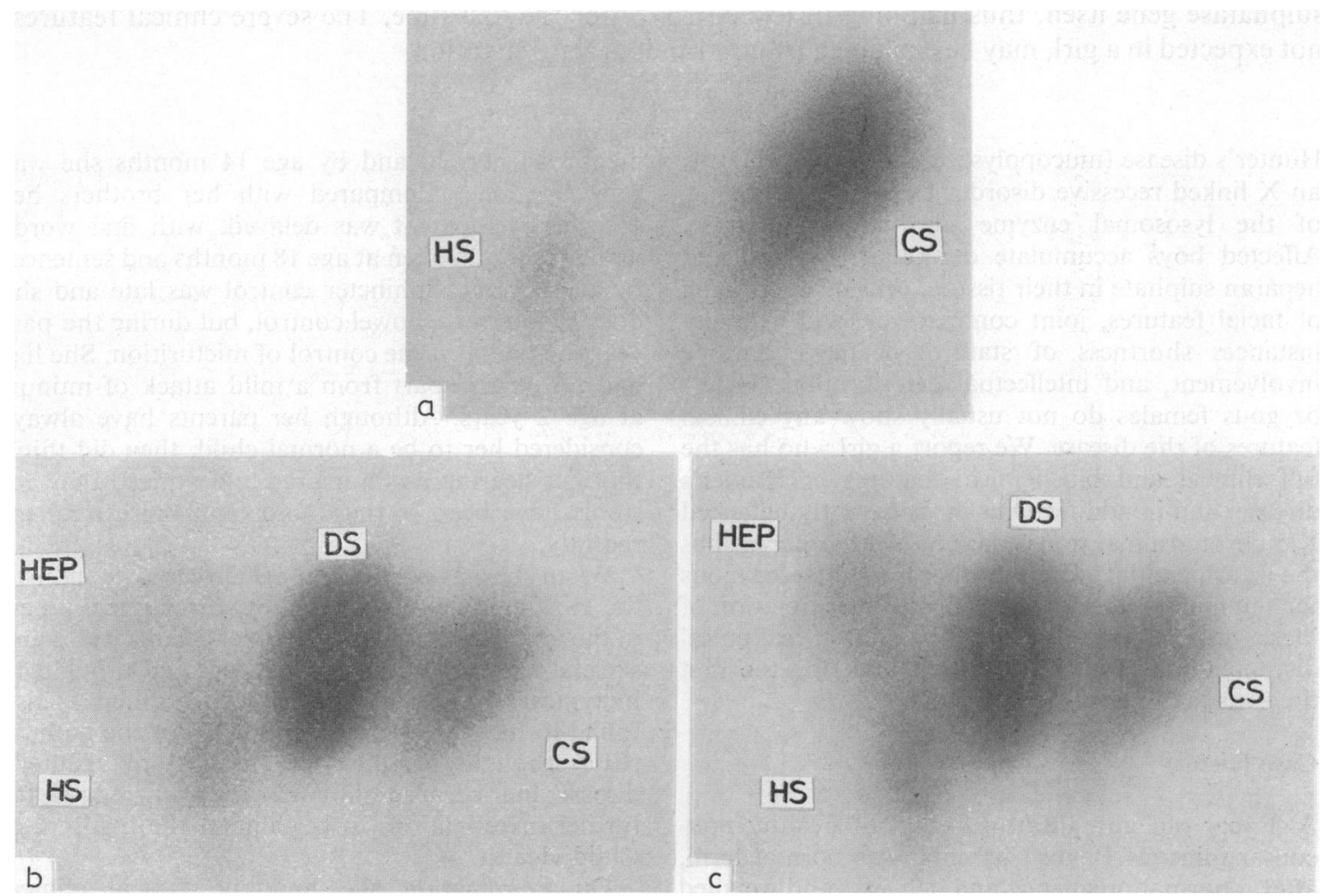

Fig. 2 Electrophoretic patterns of urinary glycosaminoglycans. (a) normal urine, (b) other known Hunter's disease patient, (c) patient.

Key: $C S=$ chondroitin sulphate; $D S=$ dermatan sulphate; $H S=$ heparan sulphate; $H E P=$ heparin-like component. 
Table Iduronate sulphatase activity in fibroblasts

\begin{tabular}{lc}
\hline & $\begin{array}{l}\text { Iduronate sulphatase } \\
\text { (nmol/mg protein/24 hrs) }\end{array}$ \\
\hline Our patient & 0 \\
Mother & 383 \\
Other known Hunter patient & 3 \\
$\begin{array}{l}\text { Normal controls }(n=8) \\
\text { (mean (SEM)) }\end{array}$ & $272(62)$ \\
\hline
\end{tabular}

heparin-like component. Their amounts are approximately equal in Hunter's disease, whereas in Hurler's disease the heparan sulphate is much more pronounced than the heparin-like component. The patient's GAG pattern was similar to that found for Hunter's disease (Fig. 2). The diagnosis was confirmed by total deficiency of iduronate sulphatase in cultured skin fibroblasts from the patient. Her mother's fibroblasts possessed a normal activity (Table). Arylsulphatase A and B activities in the patient's fibroblasts and leucocytes were normal, thus excluding a diagnosis of multiple sulphatase deficiency; normal activities were also found for $\alpha$ iduronidase, $\alpha$ mannosidase and $\beta$ galactosidase (in leucocytes); and $\beta$ glucuronidase and $\alpha$ glucosaminidase (in plasma).
Cytogenetic studies in the patient and her parents

Chromosome analysis on cultured skin fibroblasts from the patient showed a seemingly balanced reciprocal translocation between chromosomes $\mathrm{X}$ and 5. (Fig. 3). The breakpoint on the $X$ chromosome was estimated as being between q26 and q27. Her karyotype may be described as $46, \mathrm{XX}, \mathrm{t}(\mathrm{X} ; 5)$ (q2 ?7;q3 ?1) or (q2 ?6;q3 ?2). Both her parents had entirely normal karyotypes.

\section{Family studies and mother's carrier status}

The patient's mother $\left(\mathrm{I}_{2}\right)$ has two healthy sons ( $\mathrm{II}_{1}$ and $\mathrm{II}_{2}$ ) aged 7 years and 5 years, respectively, and a healthy brother $\left(I_{3}\right)$. (Fig. 4). Since her father $\left(I_{1}\right)$ is healthy with no evidence of Hunter's disease, we have to assume that she is heterozygous for the Hunter gene-the result of either a new mutation or inheritance from her mother $\left(\mathrm{I}_{2}\right)$. With an $\mathrm{X}$ linked lethal disorder, assuming an equal mutation rate in ova and sperm, on average one half of female heterozygotes represent new mutations while the other half have inherited it from their mother. In this case the one half risk that $I_{2}$ is a carrier is

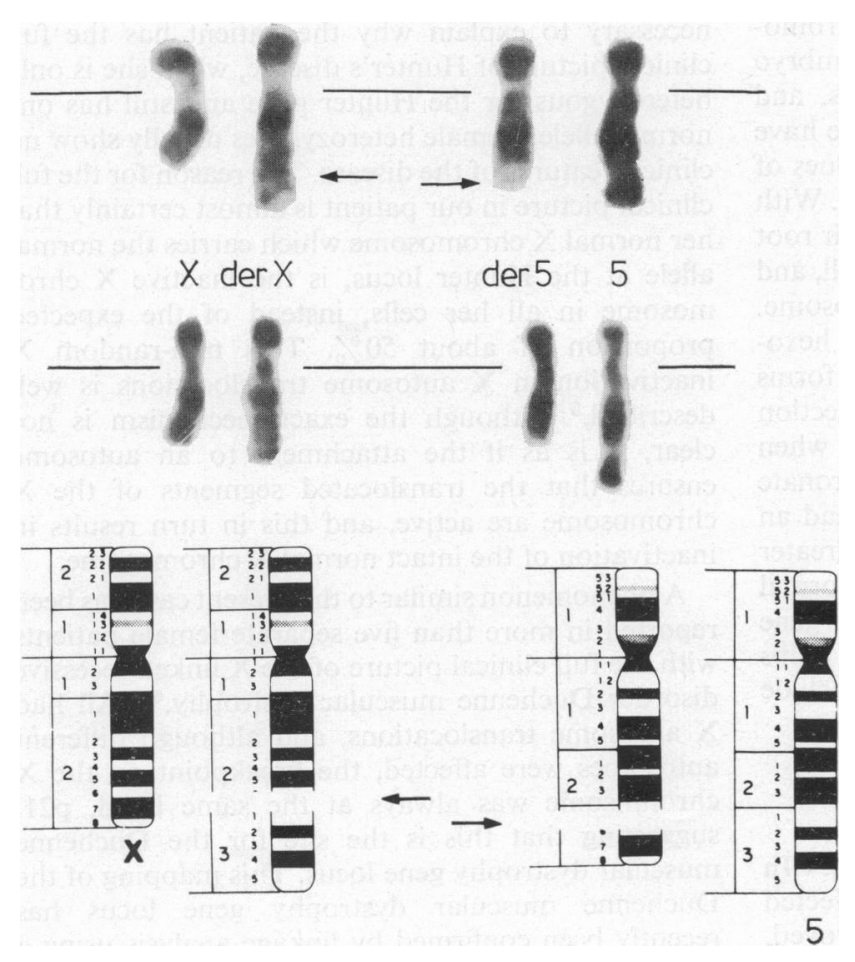

Fig. 3 Partial karyotype and idiogram showing the apparently balanced reciprocal translocation between chromosomes $X$ and 5 in the patient's fibroblasts. 


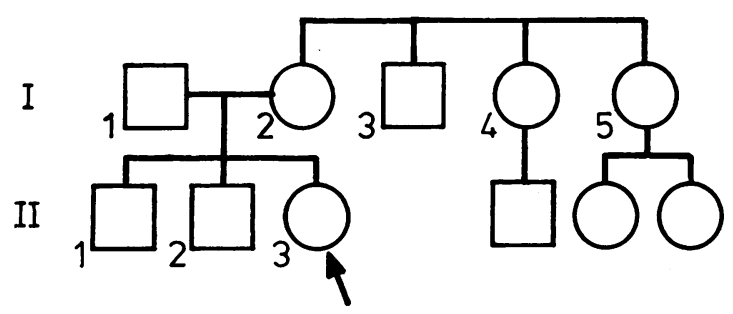

Fig. 4 Pedigree showing family members relevant to calculating the probability of the patient representing a new mutation.

modified by the fact that she has two normal sons, a normal brother, and a normal nephew; and using Baysian or relative probability methods, ${ }^{2}$ the combined risk of $I_{2}$ being a carrier for the Hunter gene is only $1 / 7$. Thus on pedigree analysis alone it is much more likely that the Hunter gene in the patient represents a new mutation rather than one inherited from $I_{2}$ (Fig. 4). $I_{2}$ had normal iduronate sulphatase activity in fibroblasts (Table). $I_{2}$ also had a serum iduronate sulphatase activity of $0.81 \mathrm{nmol} / \mathrm{hr} / \mathrm{mg}$ protein which gives a likelihood ratio of her being a carrier of $0 \cdot 4$. Combining this with the pedigree data. above it drops the risk of $I_{2}$ being a carrier to $1 / 10$.

Random inactivation of one or other $\mathrm{X}$ chromosome in any one cell in the early embryo (Lyonisation) is a normal process in females, and means that female carriers for the Hunter gene have two populations of cells; one with normal values of iduronate sulphatase activity and one deficient. With few exceptions, the cells from an individual hair root bulb represent a clone derived from a single cell, and therefore all have the same inactive $\mathrm{X}$ chromosome. Analysis of the iduronate sulphatase: hexosaminidase ratio in a series of hair root cultures forms the basis of the most reliable test to date for detection of carriers for the Hunter gene, particularly when combined with the serum activity of iduronate sulphatase. ${ }^{3} \mathrm{I}_{2}$ hair bulbs showed that $81 \%$ had an iduronate sulphatase: hexosaminidase ratio greater than $0 \cdot 1$, which lies at the lower end of the normal range. No obligatory carriers of the Hunter gene have yet been found to have $80 \%$ or more hair bulbs with a ratio greater than $0 \cdot 1$. Thus we can conclude that $\mathrm{I}_{2}$ is not a carrier for the Hunter gene.

\section{Discussion}

Hunter's disease has been reported in girls. ${ }^{4}$ In one family an affected girl also had an affected brother and although consanguinity was not proved, both parents came originally from the same small town in Lithuania. In the case of a second girl the parents were second cousins. Both had typical features of Hunter's syndrome and profound iduronate sulphatase deficiency. Both showed normal karyotypes, although in one a chromosome banding technique was not used. Cloning of the mothers' fibroblasts did not show the mosaicism expected of carriers of the ordinary $\mathrm{X}$ linked disease. It was felt that the most likely explanation was an autosomal recessive form of iduronate sulphatase deficiency. Similar cases have not been reported and one must assume the recessive form is extremely rare. It would be too much of a coincidence if the present case had such a rare recessive disease and a de novo chromosome translocation involving the $\mathrm{X}$ chromosome.

It is extremely unlikely that a de novo chromosomal translocation involving the $\mathrm{X}$ chromosome and a new mutation at a known $X$ linked gene locus should occur in the same person by coincidence. The most plausible explanation is that the translocation happened to disrupt the Hunter gene itself; thus mapping that locus to Xq26-7-the translocation breakpoint. More detailed cytogenetic studies aimed at defining the breakpoint more precisely are underway.

If the above explanation is correct, then it is still necessary to explain why the patient has the full clinical picture of Hunter's disease, when she is only heterozygous for the Hunter gene and still has one normal allele. Female heterozygotes usually show no clinical features of the disease. The reason for the full clinical picture in our patient is almost certainly that her normal X chromosome which carries the normal allele at the Hunter locus, is the inactive $X$ chromosome in all her cells, instead of the expected proportion of about $50 \%$. This non-random $\mathrm{X}$ inactivation in $X$ autosome translocations is well described. ${ }^{5}$ Although the exact mechanism is not clear, it is as if the attachment to an autosome ensures that the translocated segments of the $X$ chromosome are active, and this in turn results in inactivation of the intact normal $\mathrm{X}$ chromosome.

A phenomenon similar to the present case has been reported in more than five separate female patients with the full clinical picture of the $X$ linked recessive disorder Duchenne muscular dystrophy. ${ }^{6}$ All had $X$ autosome translocations, and although different autosomes were affected, the breakpoint on the $\mathrm{X}$ chromosome was always at the same band, p21, suggesting that this is the site for the Duchenne muscular dystrophy gene locus. This mapping of the Duchenne muscular dystrophy gene locus has recently been confirmed by linkage analysis using a 
DNA probe (lambda RC8) which maps to Xp21/ $\mathrm{Xp223.}{ }^{8} \mathrm{DNA}$ probes for various regions of the long arm of the $\mathrm{X}$ chromosome are becoming available and linkage analysis using these should allow us to confirm that the Hunter gene locus is indeed located at Xq26-7.

We thank Dr Michael Dean and Mrs Elisabeth Young for help with biochemical studies and Dr Helen Kingston and the Section of Medical Genetics, University Hospital of Wales, for the hair root analysis.

\section{References}

1 McKusick VA. Mendelian inheritance in man. 5th ed. London: Johns Hopkins University Press, 1978.

2 Bundey S. Calculation of genetic risks in Duchenne muscular dystrophy by geneticists in the United Kingdom. J Med Genet 1978;15:249-53.

3 Archer IM, Young ID, Rees DW, Oladimeji A, Wusteman FS, Harper PS, Carrier detection in Hunter syndrome. Am J Med Genet 1983;16:61-9.

4 Neufeld EF, Liebaers I, Epstein CJ, Yatziv S, Milunsky A,
Migeon BR. The Hunter syndrome in females: is there an autosomal recessive form of iduronate sulfatase deficiency? Am J Hum Genet 1977;29:455-61.

5 Therman E, Patau K. Abnormal X chromosomes in man: origin, behaviour and effects. Humangenetik $1974 ; 25: 1-16$.

6 Greenstein RM, Reardon MP, Chan TS. An X/autosome translocation in a girl with Duchenne muscular dystrophy (DMD). Evidence for DMD gene localization (abstract). Pediatr Res 1977;11:457.

7 Zatz M, Vianna-Morgenta AM, Campos P, Diament AJ. Translocation $(X ; 6)$ in a female with Duchenne muscular dystrophy: implications for the localisation of the DMD locus. J Med Genet 1981 ;18:442-7.

8 Murray JM, Davies KE, Harper PS, Meredith L, Mueller CR, Williamson $\mathbf{R}$. Linkage relationship of a cloned DNA sequence on the short arm of the $X$ chromosome to Duchenne muscular dystrophy. Nature 1982;300:69-71.

Correspondence to Dr M E Pembrey, Mothercare Unit of Paediatric Genetics, Institute of Child Health, 30 Guilford Street, London WC1N 1EH.

Received 5 July 1983 